\title{
PENETAPAN KADAR Cadmium (Cd) dan Timbal (Pb) DALAM KERANG HIJAU (Perna Viridis) DARI PERAIRAN KOTA PEKALONGAN
}

\author{
Tri Minarsih \\ Akademi Analis Kesehatan Pekalongan \\ Email : triminarsih064062@gmail.com
}

\begin{abstract}
ABSTRAK
Pekalongan dikenal sebagai kota penghasil makanan laut, termasuk kerang yang merupakan salah satu bahan makanan tambahan yang berasal dari laut yang disukai oleh masyarakat Pekalongan. Kerang adalah hewan pengumpan filter yang menyaring makanan menggunakan insang, memungkinkan untuk akumulasi logam dalam tubuh. Sifat-sifat utama logam berat adalah sulit terdegradasi, sehingga keberadaannya secara alami sulit terurai, misalnya $\mathrm{Pb}, \mathrm{Cu}, \mathrm{Cd}$ dan $\mathrm{Hg}$. Dalam penelitian ini dianalisis kandungan $\mathrm{Cd}$ dan $\mathrm{Pb}$ dalam kerang hijau yang diperoleh dari perairan Kota Pekalongan dengan Metode Visible Spektrofotometri. Hasil data menunjukkan bahwa kadar $\mathrm{Cd}$ dan $\mathrm{Pb}$ pada kerang hijau adalah $0,4644 \mathrm{ppm}(\mathrm{SD}=0,0695)$ dan $1,7915 \mathrm{ppm}(\mathrm{SD}=0,2894)$ Kandungan $\mathrm{Cd}$ dalam kerang masih sesuai dengan standar SNI 2009, karena kandungan $\mathrm{Cd}<1$ ppm, sedangkan konten $\mathrm{Pb}$ dalam cangkang melebihi standar SNI 2009, karena konten $\mathrm{Pb}>1,5$ ppm.
\end{abstract}

Kata Kunci : Kerang Hijau, Cu, Cd, Spectrophotometry Visible 


\section{ABSTRACT}

Pekalongan is known as a sea food producing city, including shellfish which is one of the additional food ingredients originating from the sea which is favored by Pekalongan people. Shellfish are filter feeder animals that filter food using gills, allowing for the accumulation of metal in the body. The main properties of heavy metals are difficult to degrade, so their existence is naturally difficult to decompose, for example $\mathrm{Pb}, \mathrm{Cu}, \mathrm{Cd}$ and $\mathrm{Hg}$. In this study analyzed the content of $\mathrm{Cd}$ and $\mathrm{Pb}$ in Green mussels obtained from the waters of Pekalongan City with the Spectrophotometry Visible Method. The data results showed that $C d$ and Pb levels in Green mussels were 0.4644 ppm $(S D=0.0695)$ and 1.7915 ppm $(S D=0.2894)$ The Cd content in the shells is still in accordance with the SNI standard 2009 , because the Cd content is $<1$ ppm, while the Pb content in the shells exceeds that of the SNI 2009 standard, because the Pb content is > 1.5 ppm.

Keywords: Green Shell, Cu, Cd, Spectrophotometry Visible

\section{PENDAHULUAN}

Salah satu masalah lingkungan wilayah pesisir Pekalongan yang akhirakhir ini mendapat perhatian serius adalah pencemaran logam berat, yang umumnya berasal dari kegiatan industri dan aktivitas manusia. Peningkatan jumlah industri dan aktivitas manusia akan selalu diikuti oleh pertambahan jumlah limbah. Logam berat tersebut di antaranya merkuri $(\mathrm{Hg})$, cadmium $(\mathrm{Cd})$, tembaga $(\mathrm{Cu})$, dan timbal $(\mathrm{Pb})$. Senyawa logam diketahui dapat terakumulasi di dalam tubuh suatu mikroorganisme dan tetap tinggal dalam jangka waktu lama sebagai racun (Supriyanto, dkk, 2008). Pekalongan dikenal sebagai kota penghasil makanan laut (Sea food), diantaranya adalah Kerang yang merupakan salah satu bahan makanan tambahan yang berasal dari laut yang digemari oleh masyarakat Pekalongan.

Kerang merupakan salah satu bahan makan tambahan hasil laut yang memperoleh makananya juga berasal dari laut, yaitu berupa plankton algae. Kerang merupakan hewan filter feeder yang menyaring makanan menggunakan insang sehingga memungkinkan terjadinya akumulasi bahan logam dalam tubuh. Sifat utama logam berat adalah sulit didegradasi, sehingga keberadaannya secara alami sulit terurai.

Manusia yang mengkonsumsi Kerang akan mengalami keracunan yang membahayakan tubuhnya karena terjadi penumpukan Kadmium dan Plumbum dalam tubuh manusia. Menurut Darmono (1995) akumulasi terjadi karena proses absorbsi logam berat ke dalam tubuh melalui saluran pernafasan dan pencernaan. Logam berat akan terakumulasi dalam jaringan tubuh bahkan menyebabkan kematian organisme tersebut, sehingga perlu ditetapkan kadar logam berat ( $\mathrm{Cd}$ dan $\mathrm{Pb}$ ) dalam Kerang Hijau..

Penelitian tentang analisis kadar $\mathrm{Cd}$ dan $\mathrm{Pb}$ dalam Kerang Hijau telah banyak dilakukan. Emma E, dkk, 2015, melakukan penelitian tentang analisis kadar $\mathrm{Pb}$ dalam Kerang Hijau di Teluk Jakarta, diperoleh kadar $\mathrm{Pb}$ sebanyak $13,98 \pm 1,92 \mathrm{mg} / \mathrm{Kg}$. Zul Alfian, 2005 
melakukan analisa kadar Logam Cadmium dari Kerang Hijau di daerah Belawan, ditemukan kadar 0,2521 \pm 0,0558 ppm. Benny Diah, dkk (2016), melakukan analysis $\mathrm{Pb}$ dan $\mathrm{Cd}$ didalam Bandeng yang dihasilkan oleh tambak Kabupaten dan Kota Pekalongan, yaitu $\mathrm{Pb}$ sebesar 0,8 ppm sedangkan Cd sebesar 0,00369 ppm. Metha Anung, dkk (2015), melakukan penetapan kadar $\mathrm{Pb}$ dalam Ikan lele yang dibudidayakan di Kota Pekalongan, dari 4 daerah lokasi budidaya diperoleh kadar $\mathrm{Pb}$ terbesar di Wilayah tirto yaitu, 39,45 $\mu \mathrm{g} / \mathrm{kg}$.

Spektrofotometri sinar tampak merupakan salah satu metode yang dapat digunakan untuk menetapkan kandungan beberapa senyawa logam, misalkan $\mathrm{Pb}$, $\mathrm{Cu}, \mathrm{Cd}$ dan Cr. Metode Spektrofotometri sinar tampak dikenal juga sebagai metode Colorimetri, dengan prinsip penngukuran intensitas radiasi yang diserap oleh larutan berwarna. Keuntungan cara ini adalah merupakan cara sederhana yang digunakan untuk menetapkan kadar senyawa yang sangat kecil. Pengembangan metode ini tidak mahal sehingga masih banyak digunakan oleh lembaga yang kecil.

\section{METODE PENELITIAN}

Pengambilan contoh sampel Kerang Hijau dilakukan di Pelabuhan Kota Pekalongan. Di pilih kerang Hijau yang masih segar yang mempunyai ukuran hamper sama. Penelitian dilakukan di Laboratorium Kimia Akademi Analis Kesehatan Pekalongan, pada Bulan Mei 2018. Bahan baku yang digunakan adalah kerang hijau (Perna viridis). Bahan untuk analisis logam berat yaitu asam nitrat p.a $65 \%$, asam perkhlorat p.a 70-72\%, dan air bebas ion serta Larutan baku $\mathrm{Cd}$ dan $\mathrm{Pb}$. Alat yang digunakan untuk preparasi bahan baku adalah timbangan analitik, jangka sorong, dan pisau dapur. Alat yang digunakan untuk analisis logam yaitu Spektrofotometer sinar tampak, Timbangan analitik, botol plastik, cawan porselen, gelas ukur, labu erlenmeyer, desikator, dan hot plate.

\section{HASIL DAN PEMBAHASAN}

a. Uji Morfologi Kerang

Tabel 1Hasil uji Morfologi kerang Hijau

\begin{tabular}{cccc}
\hline No & $\begin{array}{c}\text { Panjang } \\
(\mathbf{c m})\end{array}$ & $\begin{array}{c}\text { Lebar } \\
(\mathbf{c m})\end{array}$ & $\begin{array}{c}\text { Bobot } \\
(\text { gram })\end{array}$ \\
\hline 1 & 4,64 & 2,7 & 5,42 \\
2 & 4,05 & 2,54 & 5,2 \\
3 & 4,6 & 2,66 & 5,56 \\
\hline 4 & 4,43 & 2,9 & 5,93 \\
5 & 4,8 & 2,58 & 5,37 \\
\hline 6 & 4,29 & 2,74 & 5,86 \\
7 & 4,72 & 2,5 & 5,36 \\
\hline 8 & 4,14 & 2,5 & 5,25 \\
9 & 4,37 & 2,60 & 5,17 \\
\hline 10 & &
\end{tabular}




\begin{tabular}{cccc}
\hline & 4,9 & 2,67 & 5,86 \\
\cline { 2 - 4 } & & & \\
& & & \\
& & & \\
& & & \\
& & & \\
\hline $\mathbf{X}$ & 4.494 & 2,639 & 5.498 \\
SD & 0,269 & 0.117 & 0.274 \\
\hline
\end{tabular}

b. Kurva Kalibrasi

Tabel 2. Data Konsentrasi Vs Serapan larutan standar Cd pada panjang gelombang $228,8 \mathrm{~nm}$ secara spektrofotometer sinar tampak pada panjang gelombang $477 \mathrm{~nm}$

\begin{tabular}{lcc}
\hline No & $\begin{array}{c}\text { Konsentrasi } \\
(\mathbf{p p m})\end{array}$ & Serapan \\
\hline $\mathbf{1 .}$ & 2,0 & 0,0474 \\
\hline $\mathbf{2 .}$ & 3,0 & 0,0592 \\
\hline $\mathbf{3 .}$ & 4,0 & 0,0706 \\
\hline $\mathbf{4 .}$ & 5,0 & 0,0876 \\
$\mathbf{5 .}$ & 6,0 & 0,0982 \\
\hline
\end{tabular}

Dari tabel 2 diperoleh persamaan regresi yaitu : y $=0,013 \mathrm{x} x+0,0206$ dan koefisien korelasi (r) adalah 0,9947

Tabel 3. Data Konsentrasi Vs Serapan larutan standar Pb pada panjang gelombang $228,8 \mathrm{~nm}$ secara spektrofotometer sinar tampak pada panjang gelombang $430 \mathrm{~nm}$

\begin{tabular}{lcc}
\hline No & $\begin{array}{c}\text { Konsentrasi } \\
(\mathbf{p p m})\end{array}$ & Serapan \\
\hline $\mathbf{1 .}$ & 2,0 & 0,285 \\
\hline $\mathbf{2 .}$ & 3,0 & 0,356 \\
\hline $\mathbf{3 .}$ & 4,0 & 0,471 \\
\hline $\mathbf{4 .}$ & 5,0 & 0,567 \\
$\mathbf{5 .}$ & 6,0 & 0,673 \\
\hline
\end{tabular}


Dari data tabel 3 diperoleh persamaan regresi yaitu : $y=0,0987 \mathrm{x}+0,0756$ dan koefisien korelasi (r) adalah 0,9956

c. Penetapan Kadar $\mathrm{Cd}$ dan $\mathrm{Pb}$ dalam sampel Kerang Hijau

Tabel 4. Hasil Kadar Cd dan Pb Pada sampel kerang hijau

\begin{tabular}{ccc}
\hline No & Kadar Cd & Kadar Pb \\
sampel & & $(\mathbf{p p m})$
\end{tabular}

(ppm)

\begin{tabular}{ccc}
\hline $\mathbf{1 .}$ & 0,356 & 1,654 \\
$\mathbf{2 .}$ & 0,445 & 1,587 \\
$\mathbf{3 .}$ & 0,396 & 2,034 \\
$\mathbf{4 .}$ & 0,505 & 1,772 \\
$\mathbf{5 .}$ & 0,473 & 1,679 \\
$\mathbf{6}$ & 0,402 & \\
$\mathbf{7}$ & 0,396 & 1,824 \\
$\mathbf{8}$ & 0,599 & 1,660 \\
$\mathbf{9}$ & 0,620 & 2,126 \\
$\mathbf{1 0}$ & 0,452 & 1,674 \\
$\mathbf{X}$ & 0,4644 & 1,905 \\
$\mathbf{S D}$ & 0,0695 & 1,7915 \\
& & 0,2894
\end{tabular}

\section{PEMBAHASAN}

Pertama kali dilakukan uji morfologi untuk mengetahui panjang, lebar dan berat kerang. Dipilih kerang yang sama, karena kerang dengan berat yang sama akan mempunyai kemampuan metabolism yang sama, sehingga kadar logam yang terakumulasi di dalam tubuhnya relative juga akan sama. Dari pemeriksaan diperoleh kerang dengan panjang rata-rata $=4,494 \mathrm{~cm}( \pm 0,269)$ lebar rata-rata $=2,639 \mathrm{~cm}( \pm 0.117)$ dan 
berat rata-rata $=5,498( \pm 0,274)$. Data tersebut menunjukkan bahwa kerang memiliki mofologi yang hampir sama.

Tahap selanjutnya adalah dilakukan pembuatan kurva kalibrasi dari Larutan Baku $\mathrm{Cd}$ dan $\mathrm{Pb}$ dengan konsentrasi 2-6 ppm. Pada $\mathrm{Cd}$ diperoleh persamaan Regresi y $=0.013 x+0,0206$ dengan koefisien korelasi $(r)=0.9947$ dan pada $\mathrm{Pb}$ persamaan regressi $\mathrm{y}=0.0987 \mathrm{x}+$ 0.0756 dan koefisien korelasi $(r)=0.9956$.

Berdasarkan uji korelasi kedua standar tersebut, baik standar $\mathrm{Cd}$ maupun $\mathrm{Pb}$ mempunyai nilai $\mathrm{r}$ mendekati 1 , hal ini menunjukkan adanya korelasi yang linier antara Konsentrasi dan Serapan yang dihasilkan, dan persamaan regresi yang dihasilkan dapat digunakan untuk menghitung kadar $\mathrm{Cd}$ dan $\mathrm{Pb}$ yang terdapat di dalam sampel Kerang Hijau

Persamaan regressi yang didapatkan, digunakan untuk menghitung kadar $\mathrm{Cd}$ dan $\mathrm{Pb}$ dalam sampel kerang. Kadar Cd dalam sampel kerang adalah = 0.4644 ppm sedangkan kadar $\mathrm{Pb}$ adalah : 1,7915 ppm. Kadar Cd dalam kerang masih sesuai dengan standar SNI 2009, , karena kadar $\mathrm{Cd}<1$ ppm, sedangkan kadar $\mathrm{Pb}$ dalam kerang melebihi dari standar SNI 2009, karena kadar $\mathrm{Pb}>1.5$ ppm. Kadar $\mathrm{Pb}$ yang tinggi didalam makanan dapat menyebabkan keracunan, baik pada bayi, anak-anak maupun orang dewasa. Keracunan yang diakibatkan oleh timbal dapat berupa : penghambatan pertumbuhan pada anak-anak, kerusakan ginjal, gangguan pendengaran, gangguan pencernaan, gangguan reproduksi dan masih banyak lagi yang lainnya.

Kadar $\mathrm{Pb}$ yang diperoleh dalam penelitian ini, yaitu 1,7915 ppm $\pm 0,2894$, lebih rendah dibandingkan kadar $\mathrm{Pb}$ pada
Kerang Hijau di Teluk Jakarta, yaitu sebesar 13,98 $\pm 1,92$ ppm. Hal ini disebabkan karena zat pencemar pada umumnya dan logam $\mathrm{Pb}$ pada khususnya berasal dari limbah kegiatan industri, Teluk Jakarta merupakan muara beberapa sungai yang ada di Jakarta dan merupakan tempat pembuangan limbah industriindustri di Jakarta yang tidak mengalami Pengolahan, sehingga kadar $\mathrm{Pb}$ nya sangat tinggi (Emma E, dkk, 2015). Jumlah Industri yang membuang limbah di perairan Kota Pekalongan relative lebih sedikit, sehingga kadar $\mathrm{Pb}$ nya juga tidak terlalul tinggi.

Kadar $\mathrm{Cd}$ dan $\mathrm{Pb}$ yang diperoleh dalam penelitian ini adalah 0,4644 ppm \pm 0,0695, dan \pm lebih tinggi dibandingkan kadar $\mathrm{Cd}$ dan $\mathrm{Pb}$ pada air dan Ikan Bandeng di Tambak Kota dan Kabupaten Pekalongan, yaitu 0.00369 ppm dan 0,8 ppm (Benny D, dkk, 2005 Hal ini disebabkan karena pencemaran yang terjadi di Sungai lebih banyak dibandingkan dengan di Tambak,

Dibandingkan dengan hasil penelitian Metha Anung dkk, kadar $\mathrm{Pb}$ dalam penelitian ini juga lebih tinggi (Kadar $\mathrm{Pb}$ hasil penelitian metha $\mathrm{A}$, dkk adalah 0,3945 mg/Kg), hal ini dikarenakan sampel ikan lele yang digunakan merupakan ikan budidaya, sehingga zat pencemarnya lebih sedikit.

\section{KESIMPULAN}

Kadar Cd yang terdapat dalam kerang Hijau adalah : 0,4644 ppm $\pm 0,0695$, maasih memenuhi standar SNI 2009, sedangkan kadar $\mathrm{Pb}$ adalah 1,7915 ppm \pm 0,2894, melebihi standar SNI 2009 


\section{UCAPAN TERIMAKASIH}

1. Direktur AAK Pekalongan yang telah memberikan kesempatan untuk melakukan kegiatan Penelitian sebagai bentuk pelaksanaan Tri Dharma Perguruan Tinggi

2. Keluarga tercinta yang telah senantiasa memberikan semangat .

\section{DAFTAR PUSTAKA}

Darmono, 1995, Logam dalam system biologi Mahluk Hidup, UI Press, Jakarta

Benny D, Hadi P, Linayati, 2016, Analisis Kandungan Timbal $(\mathrm{Pb})$ Cadmium $(\mathrm{Cd})$ pada air dan ikan Bandeng di tambak Kota dan Kabupaten Pekalongan, Prosiding Seminar Nasional Tahunan ke V Hasilhasil Penelitian, Perikaanan dan Kelautan, 658-666

Emma E, Rahmad A, Ida A, 2015, Analisis Timbal dalam Kerang Hijau, Kerang Bulu dan Sedimen di Teluk Jakarta, IJPST Volume 2, Nomer 3, Oktober 2015, 105111

Fajriah N, Menggunakan AAS, J.Ilmiah Mahasiswa Pendidikan Kimia 3 (2): 162171

Eka Anastria, 2010, Skripsi, Penetapan kadar Logam Timbal dengan Metode
Spektrofotometer Sinar Tampak, UIN, Yogakarta

Metha Anung, Siska Rusmalina, Hayati, (2015), Analisis Logam Berat ( $\mathrm{Pb}$ ) pada Ikan Lele yang dibudidayakan di Kota Pekalongan, Unikal , Pekalongan

SNI, 7387-2009Zulfadli dan M.Natsir, 2017, Analisis kadar Logam Timbal (Pb) dan Cadmium $(\mathrm{Cd})$ pada tanaman Kangkung

, Batas Maksimum Cemaran Logam Berat dalam Pangan, Jakarta, BSN.

Sastrohamidjoyo, H, 2001, Dasar-dasar spektroskopi , edisi kedua, Liberty, Yogyakarta

Supriyanto C, 2008, Analisis Cemaran Logam Berat $\mathrm{Pb}, \mathrm{Cu}$ dan $\mathrm{Cd}$ pada ikan Air Tawar Dengan Metode AAS, Seminar Nasional III, SDM Teknologi Nuklir, Yogyakarta .

Underwood dan R.A day, 2001, Analisis Kimia Kuantitatif, edisi keenam, alih Bahasa Iis Sofyan, Penerbit Erlangga, Jakarta

Zul Alfian, 2005, analisa Kadar Logam Kadmium dari Kerang yang diperoleh dari daerah Belawan secara AAS. Jurnal Sains Kimia, Vol 9, No 2, 73-76.

Vogel, A.I, 1994, Kimia Analisis Kuantitatif Anorganik, edisi kesatu, alih Bahasa Pudjaatmaka. (Jakarta, Penerbit Buku Kedokteran, EGC. 